\title{
LA REFORMA CONSTITUCIONAL EN LOS ESTADOS FEDERALES ENTRE PLURALISMO TERRITORIAL Y NO TERRITORIAL
}

\section{TANIA GROPPI}

Profesora Extraordinaria de Instituciones de Derecho Público Universidad de Siena (Italia) 


\section{SUMARIO}

I. LA PARTICIPACIÓN DE LOS ESTAdOS MiEMBROS EN LA REFORMA DE LAS CONSTITUCIONES FEDERALES EN LA TEORÍA DEL FEDERALISMO... II. ...Y EN EL DERECHO COMPARADO. III. LA INCIDENCIA DE LOS ORÍGENES HISTÓRICOS DEL ESTADO FEDERAL SOBRE LA FORMA DE REVISIÓN CONSTITUCIONAL. IV. EL ENVEJECIMIENTO DE LAS FÓRMULAS «FEDERALES" DE REFORMA CONSTITUCIONAL EN EL ESTADO DEMOCRÁTICO PLURALISTA. IV. CONCLUSIONES. 


\section{LA REFORMA CONSTITUCIONAL EN LOS ESTADOS FEDERALES ENTRE PLURALISMO TERRITORIAL Y NOTERRITORIAL*}

POR

\section{TANIA GROPPI}

Profesora Extraordinaria de Instituciones de Derecho Público Universidad de Siena (Italia)

\section{LA PARTICIPACIÓN DE LOS ESTADOS MIEMBROS} EN LA REFORMA DE LAS CONSTITUCIONES FEDERALES EN LA TEORÍA DEL FEDERALISMO...

La participación, directa o indirecta, de los estados miembros en la reforma de la constitución federal es considerada por los estudiosos del federalismo y del estado federal como uno de los elementos calificadores de tales fenómenos ${ }^{1}$.

Tal consideración, derivada en parte de la observación misma de las constituciones que se suele definir como "federales", reúne a los

* Traducción al castellano de Miguel Carbonell (IIJ-UNAM, México).

1 Esto vale no solamente para los juristas, sino también para los politólogos: por todos, ver A. LIJPHART, Democracy. Patterns of majoritarian and consensus goverment in twenty-one countries (1984), trad. al castellano aumentada, Modelos de democracia. Formas de gobierno y resultados en treinta y seis países, Barcelona, Ariel, 2000. 
sostenedores de una impostación "estática" del estudio del estado federal y a los de una noción "dinámica", en el sentido del federalizing process, constituyendo quizá el más relevante punto de contacto entre las dos diferentes impostaciones metodológicas.

Los primeros sostienen que la participación de los estados miembros en la reforma constitucional connota al estado en sentido federal y hacen referencia, junto a otras características, a la solución del problema de la diferenciación del estado federal respecto a otras figuras similares, como el estado regional y la confederación de estados, así como a enfrentar la cuestión de la correspondencia de la soberanía en el ámbito del estado federal².

Para los segundos, la participación tanto del Estado central como de los estados miembros en la reforma constituye uno de los constitutional arrangments fundamentales, es decir, un aspecto del sistema de reglas dentro del cual el federalizing process se desarrolla (indispensable para poder hablar de una distinción entre comunidad nacional y comunidades locales $)^{3}$.

Desde mi punto de vista, esa necesaria implicación se liga a la función misma esencial de las constituciones federales. Independientemente del hecho de que se trate de estados federales creados por unión (de estados antes independientes) o por descentralización (de estados anteriormente unitarios), ellas nacen siempre como pactos entre comunidades territorialmente individualizadas, con la finalidad de organizar, a través de una instancia unitaria, la convivencia de sujetos portadores de identidades distintas: pactos puestos a salvo de modificaciones unilaterales, por obra de algún componente en lo individual, a través de fórmulas de modificación que requieren el consenso de mayorías calificadas de esos componentes, expresado por el voto

2 En este sentido, J. Bryce, Studies in history and jurisprudence, Oxford, 1891, pág. 173; R. CARRÉ DE MALBERG, Contribution à la théorie générale de l'État, París, 1920, I, pág. 116; H. KELSEN, Die Bundesexekution, en Festgabe für Fritz Fleiner zum 60. Geburstag (1927), trad. it.: «L'esecuzione federale. Contributo alla teoria e alla prassi dello stato federale, con particolare riguardo alla costituzione del Reich tedesco e alla costituzione federale austriacan, en La giustizia costituzionale, Milán, 1981, págs. 75 y ss.; K. C. WHEARE, Federal Government (1963), trad. it.: Del governo federale, Bolonia, 1997, pág. 120.

3 Así C. J. Friedrich, Constitutional Government and Democracy (1950), trad. it.: Governo costituzionale e democrazia, Vicenza, 1950, 295; H. LIVINGSTON, Federalism and Constitutional Changes, Oxford, 1956, 299; D. ELAZAR, Exploring Federalism (1987), trad. it.: Idee e forme del federalismo, Milán, 1995, pág. 129. 
popular o por deliberación de asambleas representativas. Solamente así puede ser preservada, por las constituciones federales, la íntima vocación para desarrollar una función integradora ${ }^{4}$ de comunidades territorialmente individualizadas. Todo procedimiento distinto sería por el contrario fuente de tensiones e impulsos disgregadores ${ }^{5}$.

\section{II. ...Y EN EL DERECHO COMPARADO}

La observación de los textos constitucionales nos muestra en efecto que, en los Estados que se suelen definir como federales, una participación de este tipo está generalmente prevista.

Sin detenerse aquí sobre las fórmulas particulares de reforma constitucional, podemos individualizar en el derecho comparado dos modalidades principales a través de las cuales sucede tal participación: a) participación indirecta en la reforma, a través de la segunda cámara; b) participación directa, a través de la ratificación de la enmienda por parte de un cierto número de entidades territoriales ${ }^{6}$.

En la primera categoría se colocan las experiencias de Alemania, Austria, Bélgica, Argentina, Sudáfrica, Brasil, Venezuela (1961): la entidad y la incidencia de la participación viene aquí a depender casi enteramente de las modalidades de elección de los componentes de la segunda cámara, no diferenciándose por tanto de la más general problemática de la participación de las entidades descentralizadas en el procedimiento legislativo. Lo que varía en el procedimiento de reforma es principalmente la mayoría requerida para la aprobación de la modificación constitucional, que es siempre superior a la mayoría simple. Por lo demás, la participación se manifiesta comúnmente en la forma de la aprobación por parte de la cámara constituida sobre la base territorial de la reforma constitucional.

4 Sobre la función de integración de las constituciones, ver G. ZAGREBELSKY, Il dirito mite, Turín, 1992, págs. 8 y ss. (trad. al castellano de Marina Gascón, Madrid, Trotta, 1997).

5 Se reenvía a T. GRopPI, Federalismo e costituzione. La revisione costituzionale negli Stati federali, Milán, 2001.

6 Solamente la Constitución argentina (artículo 30 ) prevé la participación de las provincias únicamente en la fase de la iniciativa, en cuanto el Senado expresa su voto sobre la necesidad de la reforma, que luego es sin embargo confiada a una convención electa sobre una base nacional. 
En las demás experiencias federales, por el contrario, la participación de las entidades descentralizadas en la reforma constitucional es directa, no mediada por la segunda cámara. Al respecto, hay que introducir ulteriores distinciones. Sobre todo, cuando nos referimos al necesario consenso de un cierto número de estados, se hace referencia comúnmente al voto favorable a la reforma por parte de sus órganos legislativos (en este sentido, México, Estados Unidos, Nigeria, Rusia, India, Canadá); pero en dos países (Australia y Suiza) son Ilamadas a pronunciarse directamente sobre el proyecto de reforma preparado por el parlamento nacional las poblaciones de los estados, a través de referéndum. Además, en las constituciones para cuya modificación se requiere el "consenso de los estados", varía la mayoría requerida. En muchos casos, se hace referencia a la mayoría absoluta de las entidades federativas (México, Australia, Suiza, India); en otros a los dos tercios de éstas (Rusia, Nigeria, Canadá: aquí las provincias que están a favor deben representar al menos el cincuenta por ciento de la población); en los Estados Unidos, finalmente, se alcanza el umbral de los tres cuartos.

Además de las formas, en las diversas constituciones varía la importancia de la participación: se pueden así distinguir los ordenamientos federales en los que la participación de las entidades descentralizadas abarca la modificación de cualquier disposición constitucional, con independencia de su contenido, de aquéllas en las que tal participación concierne solamente a las modificaciones relativas al arreglo federal del Estado. En verdad, el único ordenamiento que se coloca plenamente es esta categoría es Austria: en la reforma de la constitución austriaca los Länder intervienen solamente, a través del Bundesrat, cuando la reforma se refiere al reparto de competencias entre centro y periferia. En otros ordenamientos, si bien está prevista una participación (en forma más o menos fuerte) en la reforma del texto constitucional por entero, es más incisiva en el caso de los artículos relativos a la distribución de las competencias o a la formación de las segundas cámaras: este es el caso de la India, en el que la ratificación de las modificaciones constitucionales por parte de las asambleas legislativas de no menos de la mitad de los estados miembros se requiere solamente para algunas materias que tienen que ver con la relación centro-periferia; o bien en el de Sudáfri$c a$, en el que solamente las reformas relativas a las provincias o al consejo nacional de las provincias requieren del voto de al menos seis de las nuevas provincias representadas en el consejo nacional mismo. En la mayor parte de los ordenamientos, por tanto, la participación de los estados miembros en la revisión constitucional inci- 
de del mismo modo sobre la modificación de todas las disposiciones de la constitución, con independencia de que se refieran a la relación centro-periferia. Esta observación vale no sólo para las federaciones en las que la participación de las entidades descentralizadas en la reforma constitucional opera de forma particularmente "diluida", a través de la segunda cámara, sino también para aquéllas en las que la presencia de las entidades descentralizadas en el procedimiento es fuerte y directa.

En la encrucijada entre forma de la participación y materias investidas de la reforma, se coloca la posibilidad, reconocida al estado individual, de poner un verdadero y propio veto a la reforma constitucional. Así sucede, limitadamente a la representación en el Senado, en los Estados Unidos y Australia. El veto de las provincias asume particular relevancia en el ordenamiento canadiense, en el que toca materias como la representación de las provincias en el Senado, la composición de la Corte Suprema, el bilingüismo y el mismo procedimiento de reforma constitucional.

Por otro lado, debe recordarse que en algunos ordenamientos federales están previstos límites explícitos para la reforma constitucional (las llamadas unchangeable previsions o perpetuity clauses), que en ciertos casos se refieren justamente a la forma federal del Estado ${ }^{7}$. Naturalmente, en ausencia de límites explícitos, se abre, también en las constituciones federales, el problema de la determinación de los límites implícitos a la reforma, en particular de los relativos a la naturaleza federal del Estado ${ }^{8}$.

7 Así, por ejemplo, el tercer párrafo del artículo 79 de la Constitución de Alemania, según el cual no son admisibles modificaciones que afecten la articulación del Bund en Länder, la participación, en vía de principio de los Länder en la legislación (o los derechos fundamentales enunciados en los artículos 1 al 20). Una previsión de este tipo se encuentra también en la Constitución brasileña de 1988, que establece la inadmisibilidad de las propuestas de revisión dirigidas a abolir la forma federal de Estado (artículo 60). Por otro lado, es bien posible que también en ordenamientos regionales el principio de autonomía constituya un límite explícito a la reforma: la Constitución portuguesa prevé (artículo 288) que tanto la autonomía de las colectividades locales, como la autonomía política y administrativa de los archipiélagos de las Azores y de Madeira constituyen límites que las leyes de reforma deben respetar.

8 Se puede ver, por ejemplo, el debate sobre los límites implícitos para la reforma constitucional, relativos a la abolición del carácter federal del Estado, en la doctrina australiana, también en referencia a la formulación del preámbulo de la constitución de 1900. 


\section{LA INCIDENCIA DE LOS ORÍGENES HISTÓRICOS DEL ESTADO FEDERAL SOBRE LA FORMA DE REVISIÓN CONSTITUCIONAL}

En la elección de uno u otro mecanismo, es fuerte la incidencia de los orígenes históricos del Estado federal.

También en los ordenamientos federales las fórmulas de reforma son construidas a la medida de los sujetos (y por los sujetos) que se encuentran en el origen de la constitución, los cuales tienden, a través de estos mecanismos, a proyectarse en el futuro ${ }^{9}$. Se podría decirlo así: en las fórmulas de reforma constitucional se expresa la esencia, federal, del sistema político-constitucional.

Ese vínculo entre fórmula de revisión constitucional y momento genético de la constitución es más inmediatamente perceptible cuando el Estado federal nace por la unión de entidades territoriales que anteriormente estaban divididas: en estos casos, de hecho, en el origen del acuerdo se coloca justamente la voluntad de los estados, que se adhieren al pacto sobre la base de un cierto contenido y que piden poder expresarse directamente sobre las eventuales modificaciones a éste, si bien renunciando, singularmente, a ejercer el derecho de veto (a menos que las reformas incidan directamente sobre los estados en lo individual).

Por tanto, la participación directa de los estados en la reforma, a través de la ratificación de las modificaciones, está comúnmente prevista en las constituciones de ordenamientos federales nacidos por agregación, más que los que lo hacen por descentralización: es una evolución que marca el pasaje del principio de la unanimidad, característico de las experiencias confederales, al de la mayoría, para el que el consenso del estado en lo individual no es más necesario. Si bien es cierto que el caso más significativo de la correlación entre federalismo por agregación y participación directa en la reforma sigue siendo el de los Estados Unidos ${ }^{10}$, no se puede sin embargo olvidar, tam-

9 En general, sobre el vínculo entre fórmulas de revisión constitucional y momento constituyente, ver T. GROPPI, "Alle origini della rigidità costituzionale: le 'costituzioni dei moderni' di fronte al fluire del tempo", en Revista peruana de derecho constitucional, 2000, n. 2.

10 Sobre el cual se pueden ver las observaciones de A. LA Pergola, Residui "contrattualistici» e struttura federale nell'ordinamento degli Stati Uniti, Milán, 1969, pág. 289 , según el cual la técnica procedimental de la revisión ideada por los constituyentes norteamericanos traiciona la derivación del sistema federal de un ordenamiento fundado sobre el contrato, como fue el de la precedente confederación. 
bién dejando los estados "casi-federales" que prevén formas de participación directa 11 , las experiencias de Suiza, de Australia, de Canadá, que están connotadas cada una por peculiaridades propias, ligadas a específicas herencias culturales (por ejemplo el papel de la democracia directa en la tradición suiza), al contexto político-institucional (la génesis de las constituciones de Australia o de Canadá en el ámbito de la Commonwealth), o a la circulación de los modelos constitucionales (pensemos en las influencias recíprocas desarrolladas justamente entre estas cuatro constituciones, también en referencia al procedimiento de reforma).

En la misma matriz parece ser reconducible también el otro elemento que distingue los diversos tipos de participación de los entes descentralizados en la reforma constitucional, el hecho de referirse a la modificación de todo el texto de la constitución, o bien sólo a las enmiendas relativas a las disposiciones sobre el reparto de las competencias: de hecho, la participación misma en la reforma del texto completo parece ligada a la idea de que el Estado federal nace de una cesión de soberanía de entidades pre-existentes, que dan vida a un nuevo ordenamiento, según un proceso que ve a los estados como protagonistas absolutos, mientras que los ciudadanos individuales son representados por los estados mismos.

En el caso en que un Estado federal nace como consecuencia de la descentralización de un precedente Estado unitario, con la finalidad de favorecer la convivencia pacífica y la integración de entidades que, en caso contrario, se dividirían, como ha sucedido en muchas experiencias federales del siglo $X X$, en las cuales la constitución federal deriva de un compromiso entre fuerzas que son representativas de variados cleavages existentes en la sociedad, entre los cuales se encuentran también las instancias territoriales, el carácter federal del Estado viene a revestir una limitada incidencia sobre la forma de la revisión constitucional, conectándose con muchos otros elementos. En tales experiencias, la participación de los entes descentralizados en la reforma constitucional se explica esencialmente a través de su participación, más o menos incisiva, en la segunda cámara: es en definitiva la diferente composición de las dos cámaras, una formada sobre

11 Nos referimos al caso de México, Nigeria, India, Rusia y, antes de 1999, de Venezuela: todos ordenamientos en los cuales está prevista, como se ha dicho, la participación directa de los Estados miembros en la reforma de la Constitución federal, pero que difícilmente pueden ser considerados, en cuanto a su funcionamiento, como realmente federales. 
una base nacional, la otra sobre una base territorial, la que expresa, también en el ámbito de la reforma constitucional, las multiformes instancias de la sociedad pluralista.

\section{EL ENVEJECIMIENTO DE LAS FÓRMULAS «FEDERALES» DE REFORMA CONSTITUCIONAL EN EL ESTADO DEMOCRÁTICO PLURALISTA}

Si es verdad que la naturaleza del compromiso constitucional condiciona la forma del procedimiento de revisión, es también verdad que, al alejarse del momento genético del ordenamiento, puede venirse a determinar un desechamiento, un desfasamiento entre las fórmulas de reforma constitucional y la concreta realidad político-institucional, tal que vuelva irreproducible el compromiso constitucional y, en definitiva, que mine la propia idoneidad de las fórmulas de reforma para conseguir el resultado para el que fueron pensadas, o sea el de hacer la constitución modificable, pero solamente cuando en torno a las modificaciones propuestas se haya sedimentado un consenso entendido, en relación a las características del ordenamiento, como suficiente para convertir a la reforma en ocasión no de división, sino de integración.

Si el envejecimiento de las fórmulas de revisión constitucional parece valer para todos los ordenamientos, asume sin embargo un peso específico en los federales, justamente por la elevada tasa de mutabilidad que caracteriza al federalizing process, respecto al cual el cambio -en la forma de oscilación entre centralización y descentralización- constituye un elemento calificador, de modo que se puede asistir a la transformación hacia modelos unitarios de experiencias nacidas "federales" y a la descentralización de Estados centralizados, según una alternancia de idas y vueltas.

Problemas de obsolescencia de las fórmulas de revisión constitucional existen principalmente en los estados federales en los cuales para la modificación de todas las disposiciones constitucionales, y no solamente de las que se refieren al reparto de competencias, es necesario el consenso directo de un cierto número de entidades descentralizadas.

En particular, en las más antiguas experiencias federales, es difícil no ver en los procedimientos de reforma que reposan exclusivamente sobre el consenso de los estados miembros el "residuo" de un ordenamiento precedente, de naturaleza confederal, fundado sobre un 
contrato ${ }^{12}$, y es también difícil entender tales procedimientos como plenamente compatibles con el papel que la constitución del Estado federal viene, normalmente, a jugar también en relación con los individuos, además de los estados, una vez superado el momento constitutivo del ordenamiento ${ }^{13}$.

El examen de la concreta experiencia de algunos de los principales procesos de federalización de vieja data ${ }^{14}$ (in primis de los Estados Unidos) muestra que el desfase entre fórmulas de revisión constitucional y constitución material puede hacer en efecto que las verdaderas transformaciones pasen por vías diversas de la reforma constitucional, por ejemplo a través de la legislación ordinaria y las intervenciones de la Corte Suprema: frente a una fórmula de revisión que, reservando un rol central a los estados, no refleja las exigencias de modificación de un pacto que ahora ya no es más entre los estados, en tanto que es fruto al mismo tiempo de un pluralismo social e institucional, se hace siempre más amplia la fractura entre constitución escrita y constitución viviente ${ }^{15}$.

Sin embargo, cuando el principal cleavage presente en la sociedad coincide con la frontera de los estados, entonces la participación de éstos en la revisión constitucional se convierte en fundamental en todos los frentes, como testimonia el caso de Canadá, en el cual por lo demás, en presencia de una clara fractura entre dos componentes

12 Sobre la constitución norteamericana, ver A. LA PERGOLA, Residui contrattualistici, cit., págs. 289 y ss.

13 Está en crisis, entonces, la capacidad misma del sistema federal de aportar respuestas a las divisiones existentes en la sociedad: en este sentido parece compartible la posición de los autores que subrayan, aunque sea solamente en relación al elemento étnico (pero el mismo discurso podría hacerse sobre muchos otros planos), que, cuando los grupos no tienen una precisa identificación territorial, la solución federal viene temperada con otras políticas, como por ejemplo la integración del sistema federal con elementos de democracia consociativa: A. LIJPHART, Non-Majoritarian Democracy: a Comparison of Federal and Consociational Theories, en Publius, 1985, págs. 3 y ss.; así también G. Brosıo, Equilibri instabili, Politica ed economia nell'evoluzione dei sistemi federali, Turín, 1994, pág. 95.

14 Para un puntual examen de la reforma constitucional en los Estados Unidos, en Australia y en Canadá, se reenvía de nuevo a T. GROPPI, Federalismo e Costituzione, cit., págs. 143 y ss.

15 En la doctrina norteamericana sobre este tema ver al menos las fundamentales contribuciones de B. ACKERMAN, We the People: Foundations, Cambridge, Mass., 1991; Id., We the People: Transformations, Cambridge, Mass., 1998; ver también la recopilación de ensayos, Responding to Imperfection, de S. LEVINSON, Princeton, 1995. 
étnico-lingüísticos, radicados territorialmente, la única vía de salida recorrible parecería ser la confederal del consent ${ }^{16}$.

Viceversa, existen casos en los cuales los mecanismos de reforma propios del Estado federal se entrelazan con los del Estado democrático: esto sucede por ejemplo en Suiza o en Australia, donde se recurre al voto referendatario y los temas del federalismo se suman a los de la relación entre democracia directa y democracia representativa, aunque sea con éxitos profundamente diversos en los dos ordenamientos. Por una parte, de hecho, la constitución suiza ha sido objeto, desde 1874 hasta la revisión total de 1999, de ciento cuarenta modificaciones, sin que los rasgos "federales" presentes en la fórmula de revisión hayan mostrado problemas de compatibilidad con las exigencias de la democracia pluralista ${ }^{17}$. Al contrario, la constitución australiana se configura como una "constitución congelada", modificada solamente ocho veces en casi cien años de vida ${ }^{18}$, justamente por el desarrollo de una dinámica constitucional que se articula no tanto en torno al carácter federal del procedimiento, sino en la relación conflictual entre democracia directa y representativa.

Naturalmente, problemas menores existen en donde la participación de los estados en la revisión constitucional es "débil», en cuanto que se realiza a través de la segunda cámara (como en Alemania), o cuando se refiere solamente a las disposiciones constitucionales relativas a la subdivisión de las esferas de competencia entre centro y periferia (como sucede en Austria). En el primer caso, de hecho, el carácter "federal" del procedimiento es atenuado por el rol unificante desarrollado por la primera cámara y por la mediación de los partidos políticos en el momento electoral, mientras que en el segundo, estan-

16 En el sentido de que, para que se puedan dar soluciones en términos de mayorías, incluso calificadas, es necesario una affectio societatis, mientras que en caso contrario, si no es posible una impostación relativista se hace necesario elegir soluciones fundadas en la unanimidad, A. PIzzorusso, Maggioranze e minoranze, Turín, 1993, pág. 43.

17 Dejando a un lado la revisión total de 1874, en el período 1848-1978 se han contado 95 reformas: J. AUBERT, "Switzerland", en BUTLER y RANNEY, Referendum. A Comparative Study of Practice and Theory, Washington, 1978, págs. 57 y ss.; M. P. VIVIANI SCHLEIN, "La nuova costituzione svizzera: una soluzione originale", en Diritto pubblico comparato ed europeo, 1999, pág. 499, habla de 140 reformas en el período 1874-1999.

18 Frente a 44 intentos: 36 propuestas han sido bloqueadas por los electores a través del referéndum: ver B. Galligan, A Federal Republic. Australia's Constitutional System of Government, Cambridge, Mass., 1995, págs. 115 y ss. 
do sustraídas a la aprobación de los estados las reformas relativas a los derechos individuales, no se discute la cuestión de la ausencia de una participación en tales modificaciones de las fuerzas, políticas $y$ sociales, no connotadas territorialmente, que son tocadas por ellas en primera persona.

Problemas de envejecimiento y de funcionalidad de las fórmulas de reforma constitucional pueden surgir también en los ordenamientos en los que el proceso de federalización se desarrolla en dirección centrífuga, a través de la descentralización de un Estado unitario, bajo el empuje de una demanda de autonomía derivada de comunidades territoriales.

Cuando, aun en presencia de una sociedàd dividida y de un proceso de federalización en curso, como en Bélgica, o bien de fuertes minorías étnico-lingüísticas radicadas territorialmente, como en España, no están previstas incisivas formas de participación en la reforma constitucional por parte de los sujetos del pluralismo territorial, pueden surgir problemas de funcionalidad a contrario $^{19}$, en el sentido de que la escasa incidencia de las entidades territoriales sobre el proceso de reforma puede conducir a privilegiar, respecto a la revisión constitucional, la legislación ordinaria, para cuya elaboración están previstas o se desarrollan por vía de la práctica significativas formas de participación.

Este último fenómeno ha tenido lugar en Bélgica, donde la constitución misma confía, a través de muchísimas reservas, la tarea de desarrollar los rasgos fundamentales del federalismo a "leyes especiales" que parecen bastante más compatibles con la dinámica federal de lo que es el procedimiento de reforma constitucional ${ }^{20}$. Tales leyes, en el sentido del artículo 4.3 de la constitución, deben ser aprobadas con la mayoría de los votos de cada grupo lingüístico en cada una de las Cámaras, con la condición de que esté presente la mayoría de los miembros de cada grupo lingüístico y siempre que el total de los votos positivos expresados en los dos grupos lingüísticos alcance los dos tercios de los votos.

19 Ver, en sentido crítico, sobre la fallida previsión de la participación en la reforma constitucional de las entidades descentralizadas en Bélgica, M. VERDUSSEN, "Les traits constitutifs de l'État fédéral belge", en Revue générale de droit, 1998, pág. 66.

20 Así R. OrRú, "La revisione della costituzione: una procedura 'federale'?", en L'ordinamento federale belga, Turín, 1996, págs. 110 y ss., en particular, págs. 132-133. 
En España, por el contrario; en ausencia de cualquier participación real de las comunidades autónomas en la reforma constitucional, el desarrollo de las relaciones centro-periferia, por otro lado largamente desconstitucionalizadas, se ha realizado a través de una suerte de convención constitucional, los "Acuerdos Autonómicos", que son acuerdos negociados entre el Estado y las comunidades autónomas (en 1981 y 1992) sobre la base de los cuales ha sido sucesivamente creada la legislación actuativa del texto constitucional (a partir de los estatutos de autonomía) ${ }^{21}$.

Ahora bien, se pueden encontrar intentos de las entidades descentralizadas de incidir sobre la revisión de la constitución a través de la articulación en formas no previstas por la constitución misma de procedimientos de reforma. Es el caso de Italia, donde las regiones, casi ausentes del procedimiento de reforma, si se excluye la posibilidad de presentar proyectos de ley al parlamento y luego, una vez aprobada la modificación, de pedir un referéndum popular (siempre que la reforma no haya sido aprobada por las dos cámaras por mayoría de dos tercios y el referéndum sea pedido por cinco asambleas regionales) ${ }^{22}$, han intentado articular autónomamente la fase de la iniciativa, sometiendo el proyecto de ley de reforma que intentan presentar a referéndum consultivo. Es difícil no ver detrás de estas previsiones el intento de preconstituir, a través del pronunciamiento popular (especialmente si éste sucediera contextualmente en muchas regiones), un vínculo para el parlamento, que se encontraría en seria dificultad al desatender propuestas que tengan sobre la espalda un amplio consenso popular, como la Corte Constitucional italiana no ha dejado de resaltar en la decisión con la cual ha declarado la inconstitucionalidad de este modo de proceder ${ }^{23}$.

21 Permítasenos enviar de nuevo a T. Groppl, // sistema di distribuzione delle competenze tra lo stato e le comunità autonome, Turín, 1992, más bien al sucesivo, "ll regionalismo spagnolo nella prima metà degli anni novanta: il quadro normativo", en La riforma delle autonomie regionali. Esperienze e prospettive in Italia e in Spagna, de G. Rolla, Turín, 1994, págs. 143 y ss.

22 Sobre los dos instrumentos a través de los cuales las regiones pueden participar en el procedimiento de reforma constitucional, es decir, la presentación de proyectos de ley de reforma y la solicitud de referéndum, ver por ejemplo, $T$. MARTINes y A. Ruggeri, Lineamenti di diritto regionale, Milán, 2000, pág. 118.

23 Así la sentencia n. 470 de 1992, en Giur. Cost., 1992, 4252 y ss. Y la sentencia n. 496 de 2000, en Giur. Cost., 2000, págs. 3798 y ss. 


\section{CONCLUSIONES}

En definitiva, si se reconoce la importancia de la reforma constitucional en la vida de las constituciones -en cuanto también de la "manutención constitucional» depende la capacidad de la constitución formal de seguir aportando respuestas adecuadas a la propia época y de desarrollar una función de integración- viene a asumir un rol central el procedimiento a través del cual tal revisión debe suceder.

De su consonancia respecto a las fuerzas que de la constitución formal se hacen portadoras y sostenedoras - a las fuerzas, podríamos decir, que expresan una "voluntad de constitución"- depende de hecho la concreta posibilidad de realizar las modificaciones al texto constitucional advertidas como necesarias para continuar compartiéndolo y sosteniéndolo.

El examen de las constituciones de los estados comúnmente calificados como federales nos muestra que muchas de ellas prevén procedimientos de reforma en los cuales está reconocido un rol decisivo a la voluntad de las entidades descentralizadas.

La interrogante que surge, entonces, es la de la permanente adecuación de tales formas de revisión, a la luz de los caracteres asumidos por la evolución de las relaciones entre los varios componentes de la sociedad pluralista en el ámbito de estos ordenamientos. Es de hecho posible que constituciones nacidas esencialmente de la voluntad de grupos radicados territorialmente, sean luego "adoptadas", hechas propias, mantenidas con vida, gracias al sostén y al reconocimiento por parte de sujetos distintos del pluralismo, en todo caso de un pluralismo no territorial. En estos casos, la exigencia de dar voz en las decisiones fundamentales de la comunidad política al pluralismo territorial no debe sofocar las expresiones de un distinto tipo de pluralismo, no territorial, el cual, a diferencia del primero, es indudablemente la característica de las sociedades contemporáneas basadas en pertenencias y diferenciaciones que, al contrario de hace un tiempo, no encuentran en el territorio el soporte que las sostiene. 